\section{Life and death in Sumatra}

Among Orangutans: Red Apes and the Rise of Human Culture

by Carel van Schaik, with photographs by Perry van Duijnhoven

Belknap Press: 2004. 272 pp. \$29.95, £19.95, $€ 27.70$

\section{Alison Jolly}

Aceh in Sumatra was the province nearest the epicentre of the earthquake that struck on 26 December. More than 100,000 people there were killed by the resulting tsunami.

Thousands of others have died in Aceh's 25-year struggle for independence from Indonesia. One of these, called Yus, was the local head of a project to study a unique population of orangutans that gave us a new perspective into the evolution of human culture. It may seem insensitive to ask about the welfare of animals amid the human tragedy, but they too will suffer, not directly from the tsunami but from the chaos to come.

The orangutans of Aceh's lowland swamps live south of the devastated town of Meulaboh. Logging and clearing the forest profits the local people but not the orangutans. Foreign scientists have been banned from the area since 1999 because of civil strife. Carel van Schaik's field station at Suaq Balimbing was burned down by the Indonesian army, and Yus, who tried to keep it going, was killed by rebels or villagers. Among Orangutans is van Schaik's tribute to lost colleagues and the study animals he can nolonger see.

The Suaq swamp forest is misery for terrestrial humans but paradise for arboreal apes. Its rich food supply means that its red apes spend more than $40 \%$ of their time associating with others, unlike solitary orangutans elsewhere in Borneo and Sumatra. Orangutans have always been a paradox: they are champion tool-users in captivity but rarely use them in the wild. The Suaq apes are the only wild orangutans known to make and use tools, and van Schaik argues that it is social living that has allowed them to do it. One kind of tool is a short, peeled stick, which they use to pry out the fat-rich seeds of the cemengang fruit from a case defended by viciously stinging hairs. In neighbouring areas with the same fruits, the apes' lower population density means that special knowledge cannot reliably spread through a population, only from mother to infant.

Studies of the Suaq orangutans tell us that a capacity for socially transmitted culture was probably present in the ancestor of all great apes before the orangutan lineage split from the gorilla-chimp-human lineage about 13 million years ago. They also suggest that orangutans were more social when they

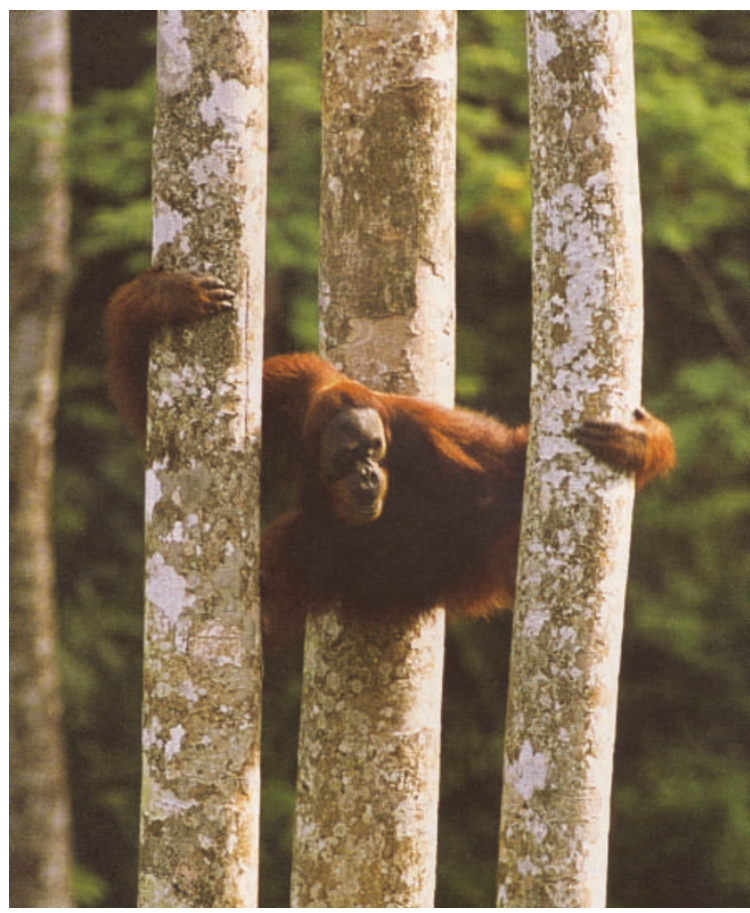

Hanging on: Aceh's orangutans survive in the face of adversity.

first evolved than most are today. Modern orangutan density and sociability have been limited by humans, who have hunted and eaten orangutans since our species arrived on Indonesia some 40,000 years ago.

Even so, the sociability of orangutans is unique among great apes. Females give birth at 8-year intervals, even in Suaq, and do not mature until they are about 15 . Males can live until they are 60 at least. This slow-motion life cycle, relative to other apes, means that a growing youngster has ample time to learn the intricacies of the forest, including the whereabouts of hundreds of individual fruit trees and the complex routes required to reach them.

A young male faces a huge life choice. He may remain as a 'subadult' for 25 years after sexual maturity, associating with other males while he sires a few infants by raping unwilling females. When he does commit to maturity, he is in a make-or-break situation. Only one big male, with huge cheek flanges and throat sack, is king of a local area of forest. His thunderous long-call warns away rivals. The local king sires almost all the infants: females come to him during oestrus. Other big males who do not successfully challenge him have no hope of further offspring. Van Schaik speculates that the sociable males of chimpanzees and humans resemble immature orangutan males, rather than the overdeveloped state of orangutan maturity.

All this is explained in clear, readable text, with beautiful photographs by Perry van Duijnhoven. Van Schaik gives just one final chapter to the Aceh conflict, the destruction of his study camp, the murder of Yus, and the bleak prospects for the Suaq swamp — without, of course, any idea of the tsunami that was to wipe out the surrounding towns, without apparently stopping the civil conflict.

A similar book published a few years ago, In the Kingdom of Gorillas (Simon \& Schuster, 2001), shows how conservation efforts can survive catastrophe. It is is the riveting personal account of Bill Weber and Amy Vedder, who spent 20 years trying to establish viable conservation in Rwanda. They joined Dian Fossey's camp at Karisoke in 1978, when poachers were killing an average of ten gorillas each year. Fossey was by then a paranoid recluse who tormented her students and rarely visited the gorillas she loved. Weber and Vedder are unsparing in their portrait of her, but recognize that she was a tragic hero in the Greek sense: her single-minded obsession was both her greatness and her destroying flaw.

The two students were horrified by the shambolic field site, run with no sensitivity for Rwandan needs or Rwandan politics, and no vision of a future different from the past. The World Bank was proposing to clear a third of the Virunga National Park's forests to raise cattle ( $40 \%$ had already been felled in 1959). Dian was paralysed, saying only: "The gorillas will all die." The two young students fought back and eventually the scheme was dropped. Weber and Vedder then spent decades helping to develop a Rwandan constituency for the national parks by local education, by using inspired Rwandan staff, and above all by establishing ecotourism. Before the 1994 genocide, in which some 800,000 Rwandans died, tourism to see the gorillas brought in a third of Rwanda's foreign exchange - the only reason why the gorillas, unlike so many humans, were spared.

Rwanda was riddled with AIDS, poverty and overpopulation, and was the epitome of hatred between neighbours. Weber and Vedder tell of the dedication of foreign conservationists, and of the heroism of Rwandans who risked their own lives to save others. Theirs is a story of hope: hope that even the worst horrors can be forgiven, and that, even in the worst catastrophes, some space for nature, and human feelings, can survive.

One of these books was written after the catastrophe of Rwanda, and one just before the catastrophe of Aceh. Both are required reading for anyone who wants to understand our nearest relatives, the great apes, in a world full of humans, and who believes that our cousins also deserve to live.

Alison Jolly is in the Department of Biology and Environmental Sciences, University of Sussex,

Brighton BN1 9QG, UK. 